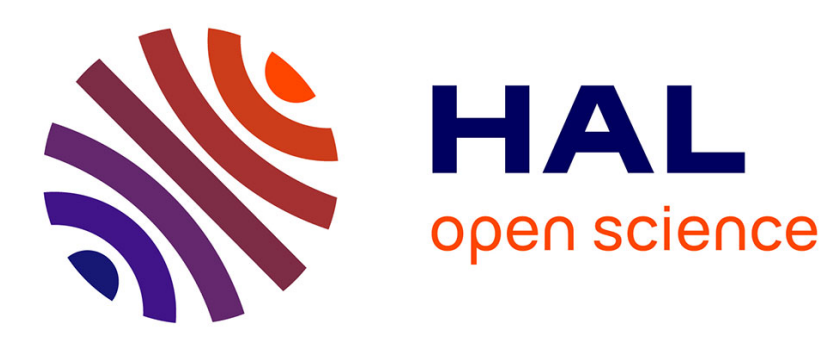

\title{
Growth stresses are highly controlled by the amount of G-layer in poplar tension wood
}

\author{
Chang-Hua Fang, Bruno Clair, Joseph Gril, Sheng-Quan Liu
}

\section{To cite this version:}

Chang-Hua Fang, Bruno Clair, Joseph Gril, Sheng-Quan Liu. Growth stresses are highly controlled by the amount of G-layer in poplar tension wood. IAWA Journal, 2008, 29 (3), pp.237-246. 10.1163/22941932-90000183 . hal-00339066

\section{HAL Id: hal-00339066 https://hal.science/hal-00339066}

Submitted on 15 Nov 2008

HAL is a multi-disciplinary open access archive for the deposit and dissemination of scientific research documents, whether they are published or not. The documents may come from teaching and research institutions in France or abroad, or from public or private research centers.
L'archive ouverte pluridisciplinaire HAL, est destinée au dépôt et à la diffusion de documents scientifiques de niveau recherche, publiés ou non, émanant des établissements d'enseignement et de recherche français ou étrangers, des laboratoires publics ou privés. 


\title{
GROWTH STRESSES ARE HIGHLY CONTROLLED BY THE AMOUNT OF G-LAYER IN POPLAR TENSION WOOD.
}

5

1) Laboratoire de Mécanique et Génie Civil (LMGC), Université Montpellier 2, CNRS, Montpellier, France 2) Forest Products Department, Anhui Agricultural University, Hefei, China

Corresponding author: Bruno CLAIR

e-mail: clair@lmgc.univ-montp2.fr

Tel : $+33-467144918$

Fax : $+33-467144792$

2008, IAWA Journal, 29 (3), 237-246

15

\begin{abstract}
To determine how gelatinous fibres and gelatinous layers contribute to the magnitude of longitudinal growth stress in tension wood, anatomical measurements of gelatinous fibres were carried out on poplar tension wood (Populus I4551). It was found that (a) no gelatinous fibres were observed under a growth strain level of 0.06 to $0.08 \%$; (b) almost $100 \%$ of the non-conductive tissues contained gelatinous fibres above a growth strain level of 0.15 to $0.19 \%$; and (c) the area of fibres, the area of fibres with gelatinous layers per unit of tissue area, and the thickness of the gelatinous layers predominantly influence the magnitude of growth stress.
\end{abstract}

Key-words: gelatinous fibre, gelatinous layer, growth strain, growth stress, tension wood, poplar 


\section{INTRODUCTION}

Trees produce asymmetric growth stresses to maintain the vertical orientation of the main stem or the angle of a branch, in order to receive sufficient light or in response to a strong dominant wind. This is usually achieved by the production of reaction wood, often combined with eccentric growth. While gymnosperms produce compression wood on the lower side of leaning stems, angiosperms produce tension wood generating high tensile stresses on their upper side (Wardrop 1964; Fisher \& Stevenson 1981). Both strategies allow strongly heterogeneous growth stress distribution at the periphery of stems, generating the bending moments required to control their shape.

Normal wood fibres are composed of a thin primary wall and a thick secondary wall divided into 3 sub-layers; the $\mathrm{S}_{1}, \mathrm{~S}_{2}$ and $\mathrm{S}_{3}$ layers. In many hardwood species

40 such as beech, poplar, oak and chestnut, tension wood contains fibres with a special morphology and chemical composition due to the development of the socalled gelatinous layer (G-layer) (Onaka 1949) that replaces the $S_{3}$ layer and a part or the whole of the $S_{2}$ layer (Saiki 1971). The G-layer is known to have a high cellulose content with a high degree of crystallinity (Norberg \& Meier 1966;

45 Côté et al. 1969) and to contain microfibrils oriented along the axis of the cell (Fujita et al. 1974).

There is some disagreement about the origin of growth stresses in wood (Boyd 1985; Bamber 1987; Yamamoto \& Okuyama 1988; Okuyama et al. 1994; Yamamoto 1998; Bamber 2001). While it is known that some species do not need

50 to produce G-layer to induce high growth stresses (Okuyama et al. 1994; Yoshida et al. 2000; Clair et al. 2006b), tension wood with a G-layer is a good model for trying to understand growth stress generation. In this paper we will concentrate on the contribution of the G-layer to the magnitude of growth stresses in tension wood. Is it the percentage of fibres, the percentage of fibres with a G-layer (Gfibres) or the thickness of the G-layer in the G-fibres?

Previous studies (Okuyama et al. 1994; Yamamoto et al. 2005) have examined similar questions, but G-layer quantification was biased by its swollen appearance always observed on sliding microtome sections (Clair et al. 2005a). Moreover, this artefact was possibly influenced by the growth stress level, so that the bias introduced in the previous findings could have been even greater. In this study measurements were done on embedded sections to avoid this artefact and thus allow a correct quantification of the G-layer.

\section{MATERIALS AND METHODS}

The experiments were performed on poplar tension wood (Populus I4551). Poplar tension wood has fibres with a gelatinous (G-) layer and exibits high longitudinal 
tensile stress. The tension wood samples were obtained from a 15-year-old leaning tree growing in a plantation near Montpellier in the south of France. The tree was chosen because it was leaning and there was evidence that there was an active process to restore the stem to a vertical orientation.

\section{Growth Strain (GS)}

The presence of tension wood was confirmed by the measurement of residual growth strains using the strain gauge method described in Yoshida and Okuyama (2002). Measurement of longitudinal growth strain (GS) was done at 25 positions around the surface of an inclined poplar trunk at 4 different heights. GS is directly correlated to the growth stress level within trees of a same species (Archer 1986; Fournier et al. 1994). As all the GS values were negative, absolute GS values were used to simplify representation and analysis. GS values ranging from $0.01 \%$ to $0.23 \%$ were obtained with the highest values from the upper side of the stem and lowest values from the lateral and lower sides of the stem. As the study

80 focused on the role of the G-layer and none or very few G-layers were found microscopically in the samples with GS values up to $0.06 \%, 5$ samples with GS values regularly spread from 0.08 to $0.23 \%(0.23,0.19,0.15,0.12$ and $0.08 \%)$ were chosen for anatomical studies.

\section{Sample preparation}

85 Samples were taken from the respective GS measurement positions and placed in water as soon as they were taken from the tree. As normal sectioning methods with a sliding microtome results in an uncontrolled transverse swelling and detachment of the G-layer in poplar (Clair et al. 2005a; Clair et al. 2005b), embedded wood samples were used and serial-sectioning was performed with a

90 glass knife.

Wood samples ( $2 \mathrm{~mm}$ in the longitudinal direction, $1 \mathrm{~mm} \times 1 \mathrm{~mm}$ in cross section) were longitudinally cut by splitting. They were then cut mid length, perpendicular to the fibre direction, with a new razor blade to obtain two matched samples (one was used for this study, and the other used to examine the drying

95 shrinkage of G-layer (Fang et al. in press 2007)).

The samples were dehydrated with ethanol and embedded in LR White resin (two exchanges of resin/ethanol mixture for 1 hour, followed by two exchanges in pure resin for 1 hour and kept overnight at room temperature, then polymerised at $65^{\circ} \mathrm{C}$ overnight). After polymerisation of the resin, tissue deformation is

100 prevented, and further sectioning will not alter the shape and the size of the cell wall layers.

\section{Sectioning}


Serial transverse sections ( $2.5 \mu \mathrm{m}$ thickness) were performed with a glass knife and distance from the upper surface (border) was recorded for each section. For each sample more than 100 sections were obtained, mounted on glass slides and observed under an optical microscope.

To avoid measurement of the G-layer in a swollen state (Clair et al. 2005a), we plotted, for each of the 5 samples, the variation of the mean G-layer thickness (MGLT, measured as explained below) with the distance from the border (Fig. 1).

110 MGLT became almost stable when the distance from the border reached 70 to $120 \mu \mathrm{m}$, depending on the sample. In this paper we will focus on these stabilised values, as they provide a good indication of the undisturbed morphology of the cell wall of tension wood cells, and in our opinion, as the cell wall was in the living tree. For each sample the values of the last 5 or 6 measured sections were 115 used for measurements.

\section{Measurement}

Images (Fig. 2) were obtained with a digital camera and measurements obtained with ImageJ 1.34s and Optimas v6.5 image analysis software.

At the tissue scale, for each sample, measurements of vessel area were performed

120 on images (magnification X100) covering the whole section and measurements of G-fibres area were performed on 5 images (magnification X500) ordered in the radial direction. The following parameters were measured:

Total area: $\quad A_{T}$

Vessels area: $A_{V}$

125 G-fibres area: $A_{G F s}$

This allows the calculation of the following parameters:

Fibre area: $\quad A_{F}=A_{T}-A_{V}$ (assuming ray area is negligible)

Fibre area ratio: $F R=A_{F} / A_{T}=1-\left(A_{V} / A_{T}\right)$

Area ratio of G-fibres among fibres: $G F R_{F}=A_{G F s} / A_{F}$

$130 \quad$ Area ratio of G-fibres among total area: $G F R_{T}=A_{G F s} / A_{T}$

At the fibre scale, for each sample, on each section, the same 10 to $12 \mathrm{G}$-fibres were followed from the sample border to 100 - $200 \mu \mathrm{m}$ deep in the sample (Fig. 1). The following parameters (Fig. 3) were measured for each of the 10 to 12

135 fibres (radial and tangential directions determined as parallel and perpendicular to the rays respectively):

Fibre diameters: $D_{r}, D_{t}$ (respectively in radial and tangential directions)

G-layer thickness (measured on both side of the fibre): $G L T_{r 1}, G L T_{r 2}$ in radial direction and $G L T_{t 1}, G L T_{t 2}$ in tangential direction 
140 In order to estimate the surface area of the G-fibre and G-layer, two simplifying assumptions were made: (1) the shape of the cell is circular; and (2) the thickness of other cell wall layers ignored (since they are usually very thin in the observed G-fibre). Based on these assumptions, the following parameters were calculated:

$$
\text { Mean fibre diameter: } \quad F D=(D r+D t) / 2
$$

145 Mean G-layer thickness in a fibre:

$$
G L T=\left(G L T_{r 1}+G L T_{r 2}+G L T_{t 1}+G L T_{t 2}\right) / 4
$$

Mean G-layer thickness in a section: $M G L T=\Sigma G L T / n(\mathrm{n}=10$ to 12$)$

$$
\begin{array}{ll}
\text { G-fibre area: } & A_{G F}=(\pi / 4) \times F D^{2} \\
\text { G-layer area: } & A_{G L}=(\pi / 4) \times\left[F D^{2}-(F D-2 \times G L T)^{2}\right]
\end{array}
$$

150 Area ratio of G-layer in G-fibre:

$$
G L R_{G F}=A_{G L} / A_{G F}=4 \times(G L T / F D) \times(1-G L T / F D)
$$

This allows the area ratio of G-fibre and G-layer in the whole section to be estimated:

Area ratio of G-fibre among total area: $G F R_{T}=G F R_{F} \times F R$

Area ratio of G-layer among total area: $G L R_{T}=G L R_{G F} \times G F R_{T}$

\section{RESULTS AND DISCUSSION}

\section{Relationship between GS and tissue surface ratios}

160 Table 1 shows the average values of $G F R_{F}, F R$ and $G F R_{T}$ for the different samples. In the sample with GS value of $0.06 \%$ or less, none or very few G-layers were observed. The possible existence of a threshold of G-fibre occurrence between 0.06 and $0.08 \%$ can be hypothesized. A similar result was obtained by Washusen et al. (2003) in Eucalyptus globulus. Another threshold was also 165 observed above 0.15 and $0.19 \%$ where almost all fibres were G-fibre. Both thresholds, however, are hypothetical as they would need to be confirmed by other observations.

Jourez et al. (2001) found a lower vessel lumen ratio in tension wood than in opposite wood for poplar and Ruelle et al. (2006) confirmed this observation in

17021 tropical species. The present study confirms that this tendency holds within tension wood samples with different GS since the total fibre ratio $(F R)$ was significantly correlated to GS (at the 0.05 level with a 2-tailed test, $r=0.909$ ). However this ratio varies in a very narrow range (Table 1) and it appears doubtful that fibre percentage could explain the change in GS. On the other hand, the $G F R_{T}$ has a significant positive correlation with GS (at the 0.05 level with a 2- 
tailed test, $\mathrm{r}=0.884$ ), as previously observed (Clair et al. 2003; Washusen et al. 2003). In combination with the results of this study, we can presume that fibre ratio does play some role in growth stress generation. However $G F R_{T}$ has the most important effect.

\section{Relationships between GS and microscopic features}

Table 1 allows us to separate our G-fibre samples into two groups. For samples 1 and 2, where almost $100 \%$ of the fibre tissues were identified as G-fibres, $G F R_{T}$ was approximately $75 \%$, while samples 3 to 5 had a $G F R_{T}$ close to $50 \%$. However, both groups correspond to large ranges of GS values. Clearly an analysis at a finer scale is required to understand the origins of these GS variations: were more G-layers produced, or different G-layers?

The thickness of the G layers, given here by $G L T$, is a first approach to quantify the amount of G layers. Fig. 4 shows a considerable scatter of GLT measurements for each GS level, although a positive trend can be observed in the relationship

190 between GLT and GS. Within each sample corresponding to a given GS, GLT was positively correlated with $F D$, with similar slopes (Fig. 5). This can be explained by GLT variation along a G-fibre. Okumura et al. (1977) reported that the G-layer is thickest in the mid-region of the fibre and apparently gets thinner toward the tips. Hence it is necessary to control fibre diameter when comparing GLT. When a

195 partial correlation analysis method controlling cell diameter $F D$ was used, a highly significant positive correlation $(\mathrm{r}=0.734, \mathrm{p}<0.001)$ was found between GS and GLT which indicates that at the same level of cell diameter, thicker G-layer accompanies higher GS. This can be explained by the accumulation effect of each unit of microfibrils. It also confirms that in G-fibres it is the G-layer that plays the major role in the growth stress generation process.

\section{Relationships between GS and G-layer proportion $\left(G L R_{T}\right)$}

Table 2 shows that the $G L R_{T}$, calculated according to equation (5), is significantly correlated to GS (Pearson $\mathrm{r}=0.846, \mathrm{p}<0.001$ ) (Fig. 6) and indicates that a higher proportion of G-layer in tension wood produces higher growth stress. The relationship is highly significant and suggests that the amount of G-layer is largely controlling the stress level.

Some inconsistency was observed between samples 3 and 4. As shown in Table 1, Fig. 4 and 6, sample 3 has lower $G F R_{T}$, thinner mean $G L T$ and lower $G L R_{T}$ than sample 4, but a higher GS. Similarly, Washusen et al. (2003) reported that some

210 tissue exhibited high GS with few G-fibres. They explained that it could be attributed to a local heterogeneity in the amount of G-layer.

Some authors have shown differences in cellulose organisation or crystallite size between normal and G-fibre secondary wall (Washusen \& Evans 2001; 
Donaldson 2007; Ruelle et al. 2007b); however these studies did not check if 215 these changes occur in the G-layer of samples having low to high tension wood. Our results show that a change of structure or composition of G-layer is not needed to explain the increase of GS: the amount of G-layer could be sufficient to control the tensile stress level. Recently, Ruelle et al. (2007a) showed that crystal size increases with growth stress, even in species not producing tension wood

220 with a G-layer.

\section{CONCLUSIONS}

No G-fibres were observed for a GS up to $0.06 \%$ while their surface ratio amounted to $50 \%$ or more for GS greater than $0.08 \%$, suggesting a hypothetical threshold for G-fibres occurrence between these two GS values. Almost 100\% of the fibres contained G-fibres above another hypothetical GS threshold between 0.15 and $0.19 \%$.

In the samples examined, more G-fibres per unit of tissue area and thicker G-layer accompany higher longitudinal growth stress (proportional to GS) in tension

230 wood with G-fibres and suggests that these factors contribute to growth stress generation and therefore the G-layer plays the most important role in high growth stress generation. This may be explained by the hypothesis that the tensile stress of microfibrils governs the longitudinal tensile stress in tension wood (Bamber 1978; Okuyama et al. 1986; Bamber 1987; Clair et al. 2006a).

\section{ACKNOWLEDGEMENTS}

The authors thank the reviewers for their work to improve the quality of the manuscript. This research has been supported by the French National Research Agency (ANR).

\section{REFERENCES}

240 Archer, R.R. 1986. Growth stresses and strains in trees. Springer Verlag, Berlin/Heidelberg/New York, 240 pp.

Bamber, R.K. 1978. The origin of growth stresses Contributed paper, IUFRO Conference, Wood quality and utilization of tropical species. Laguna, Philippines, 1978, pp. 7.

245 Bamber, R.K. 1987. The origin of growth stresses: a rebuttal. IAWA Bull., n. s., 8(1): 80-84.

Bamber, R.K. 2001. A general theory for the origin of growth stresses in reaction wood : how trees stay upright. IAWA J., 22(3): 205-212.

Boyd, J.D. 1985. The key factor in growth stress generation in trees: lignification 
or crystallisation. IAWA Bull., 6: 139-150.

Clair, B., T. Alméras, H. Yamamoto, T. Okuyama \& J. Sugiyama. 2006a. Mechanical behavior of cellulose microfibrils in tension wood in relation with maturation stress generation. Biophys. J., 91(3): 1128-1135.

Clair, B., J. Gril, K. Baba, B. Thibaut \& J. Sugiyama. 2005a. Precautions for the structural analysis of the gelatinous layer in tension wood. IAWA J., 26(2): 189-195.

Clair, B., J. Ruelle, J. Beauchêne, M.-F. Prévost \& M. Fournier Djimbi. 2006b. Tension wood and opposite wood in 21 tropical rain forest species. 1. Occurrence and efficiency of the G-layer. IAWA J., 27(3): 329-338.

260 Clair, B., J. Ruelle \& B. Thibaut. 2003. Relationship between growth stress, mechanical-physical properties and proportion of fibre with gelatinous layer in Chestnut (Castanea sativa Mill.). Holzforschung, 57(2): 189-195.

Clair, B., B. Thibaut \& J. Sugiyama. 2005b. On the detachment of the gelatinous layer in tension wood fiber. J. Wood Sci., 51(3): 218-221.

Côté, W.A.J., A.C. Day \& T.E. Timell. 1969. A contribution to the ultrastructure of tension wood fibers. Wood Sci. Technol., 3(4): 257-271.

Donaldson, L. 2007. Cellulose microfibril aggregates and their size variation with cell wall type. Wood Sci. Technol., 41: 443-460.

Fang, C., B. Clair, T. Alméras \& J. Gril. in press 2007. Transverse shrinkage of poplar tension wood at cell wall level. Wood Sci. Technol., first online DOI 10.1007/s00226-007-0148-3.

Fisher, J.B. \& J.W. Stevenson. 1981. Occurence of reaction wood in branches of Dicotyledons and its role in tree architecture. Bot. Gaz., 142(1): 82-95.

Fournier, M., B. Chanson, B. Thibaut \& D. Guitard. 1994. Measurement of residual growth strains at the stem surface. Observations of different species (in French). Ann. Sci. For., 51(3): 249-266.

Fujita, M., H. Saiki \& H. Harada. 1974. Electron microscopy of microtubules and cellulose microfibrils in secondary wall formation of poplar tension wood fibers. Mokuzai Gakkaishi, 20(4): 147-156.

280 Jourez, B., A. Riboux \& A. Leclercq. 2001. Anatomical characteristics of tension wood and opposite wood in young inclined stems of poplar (Populus euramericana $\mathrm{cv}$ " ghoy "). IAWA J., 22(2): 133-157.

Norberg, P.H. \& H. Meier. 1966. Physical and chemical properties of the gelatinous layer in tension wood fibre of aspen (Populus tremula L). Holzforschung, 20: 174-178.

Okumura, S., H. Harada \& H. Saiki. 1977. Thickness variation of the G-layer along a mature and a differentiating tension wood fiber in Populus euramericana. Wood Sci. Technol., 11: 23-32. 
Okuyama, T., Kawai A., Kikata Y. and Yamamoto H. 1986. The growth stresses in reaction wood, Proc IUFRO-18 Word Congress Div 5, Ljubljana, Yugoslavia, pp. 249-260.

Okuyama, T., H. Yamamoto, M. Yoshida, Y. Hattori \& R.R. Archer. 1994. Growth stresses in tension wood : role of microfibrils and lignification. Ann. Sci. For., 51(3): 291-300.

295 Onaka, F. 1949. Studies on compression and tension wood. Wood research, Bulletin of the Wood research Institute, Kyoto University, Japan, 24(3): 188.

Ruelle, J., B. Clair, J. Beauchêne, M.F. Prevost \& M. Fournier. 2006. Tension wood and opposite wood in 21 tropical rain forest species. 2. Comparison of some anatomical and ultrastructural criteria. IAWA J., 27(4): 341-376.

Ruelle, J., H. Yamamoto \& B. Thibaut. 2007a. Growth stresses and cellulose structural parametres in tension wood from three tropical rainforest angiosperm species. BioRes., 2(2): 235-251.

Ruelle, J., M. Yoshida, B. Clair \& B. Thibaut. 2007b. Peculiar tension wood structure in Laetia procera (Poepp.) Eichl. (Flacourtiaceae). Trees, 21(3): 45-355.

Saiki, H.a.O., K. 1971. Cell wall organization of gelatinous fibers in tension wood. Bull. Kyoto Univ. For., 42: 210-220.

Wardrop, A.B. 1964. The reaction anatomy of arborescent angiosperms. In: M.H.

310 Zimmermann (Editor), The formation of wood in forest tree. Academic Press, New York, pp. 405-456.

Washusen, R. \& R. Evans. 2001. The association between cellulose crystallite width and tension wood occurrence in Eucalyptus globulus. IAWA J., 22(3): 235-243.

315 Washusen, R., J. Ilic \& G. Waugh. 2003. The relationship between longitudinal growth strain and the occurrence of gelatinous fibers in 10 and 11-year-old Eucalyptus globulus Labill. Holz als Roh- und Werkstoff, 61(4): 299 303.

Yamamoto, H. 1998. Generation mechanism of growth stresses in wood cell walls: roles of lignin deposition and cellulose microfibril during cell wall maturation. Wood Sci. Technol., 32(3): 171-182.

Yamamoto, H., K. Abe, Y. Arakawa, T. Okuyama \& J. Gril. 2005. Role of the gelatinous layer (G-layer) on the origin of the physical properties of the tension wood of Acer sieboldianum. J. Wood Sci., 51(3): 222-233.

325 Yamamoto, H. \& T. Okuyama. 1988. Analysis of the generation process of growth stresses in cell walls. Mokuzai Gakkaishi, 34(10): 788-793.

Yoshida, M., T. Okuda \& T. Okuyama. 2000. Tension wood and growth stress 
induced by artificial inclination in Liriodendron tulipifera Linn. and Prunus spachiana Kitamura f. ascendens Kitamura. Ann. For. Sci., 57(8): 739-746.

Yoshida, M. \& T. Okuyama. 2002. Techniques for measuring growth stress on the xylem surface using strain and dial gauges. Holzforschung, 56(5): 461467. 
Table 1. Average values of $G F R_{F}, F R$ and $G F R_{T}$ for different GS values.

\begin{tabular}{ccccc}
\hline Sample & $\begin{array}{c}\text { GS } \\
(\%)\end{array}$ & GFR $_{\mathrm{F}}(\%)$ & $\mathrm{FR}(\%)$ & $\mathrm{GFR}_{\mathrm{T}}(\%)$ \\
\hline 1 & 0.23 & $\approx 100.0$ & 75.0 & 75.0 \\
2 & 0.19 & $\approx 100.0$ & 74.9 & 74.9 \\
3 & 0.15 & 69.0 & 74.1 & 51.1 \\
4 & 0.12 & 73.8 & 72.8 & 53.7 \\
5 & 0.08 & 68.0 & 73.3 & 49.9 \\
\hline
\end{tabular}

Table 2. Average value of $G L R_{T}(\%)$ for different GS values (\%).

\begin{tabular}{ccccc}
\hline Sample & $\begin{array}{c}\text { GS }(\%) \\
(\%)\end{array}$ & GLR $_{\mathrm{T}}(\%)$ & $\mathrm{N}$ & Std. Deviation \\
\hline 1 & 0.23 & 30.6 & 48 & 2.1 \\
2 & 0.19 & 23.9 & 58 & 2.7 \\
3 & 0.15 & 13.3 & 50 & 1.4 \\
4 & 0.12 & 16.4 & 50 & 2.3 \\
5 & 0.08 & 13.2 & 60 & 1.3 \\
\hline
\end{tabular}

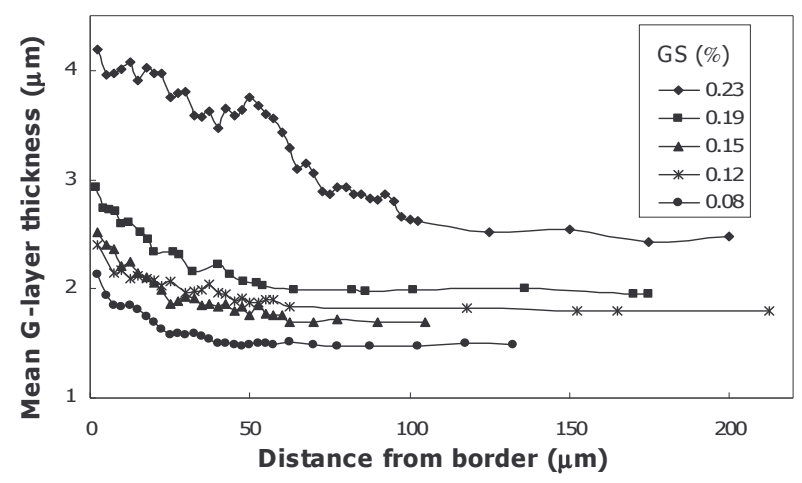

340 Fig. 1. Mean G-layer thickness $(M G L T, \mu \mathrm{m})$ variation with the distance from the border for 5 samples with different GS values. 


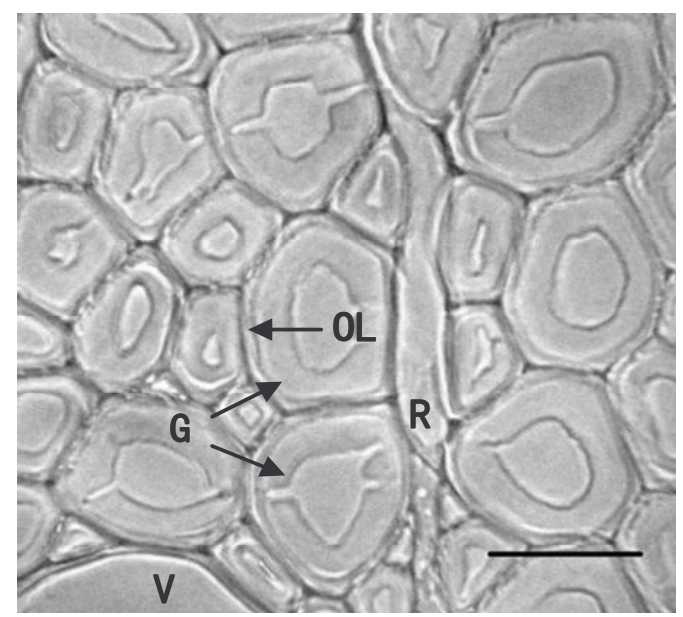

Fig. 2. Transverse section of sample 1. G: G- Fig. 3. Detail of figure 2 presenting the G-layer layer; OL: other cell wall layers including compound lamella, $\mathrm{S}_{1}$ and $\mathrm{S}_{2}$; V: vessel; R: ray. Scale bar $=20 \mu \mathrm{m}$.
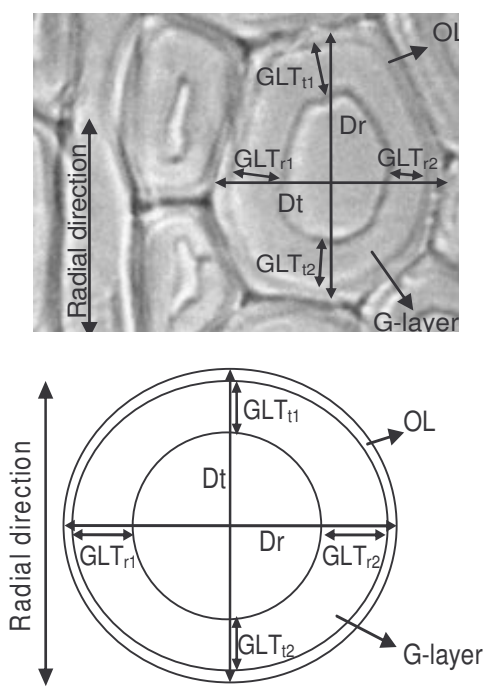

thickness and cell diameter measurements. G-layer thickness was always measured in the same 4 positions (2 radial: $\left(\mathrm{GLT}_{\mathrm{rl}}, \mathrm{GLT}_{\mathrm{r} 2}\right)$ and 2 tangential: $\left(\mathrm{GLT}_{\mathrm{t} 1}\right.$, $\left.\mathrm{GLT}_{\mathrm{t} 2}\right)$ ). Cell diameter was measured in 2 directions (radial: Dr and tangential: Dt).

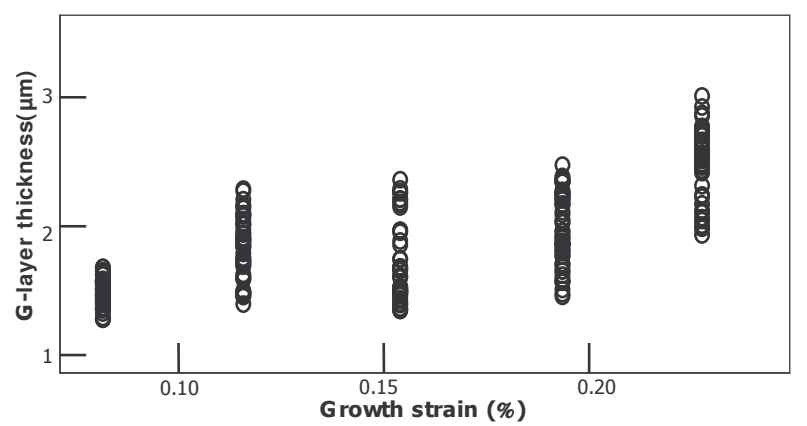

Fig. 4. Relation between G-layer thickness $(G L T, \mu \mathrm{m})$ and growth strain (GS, \%). 


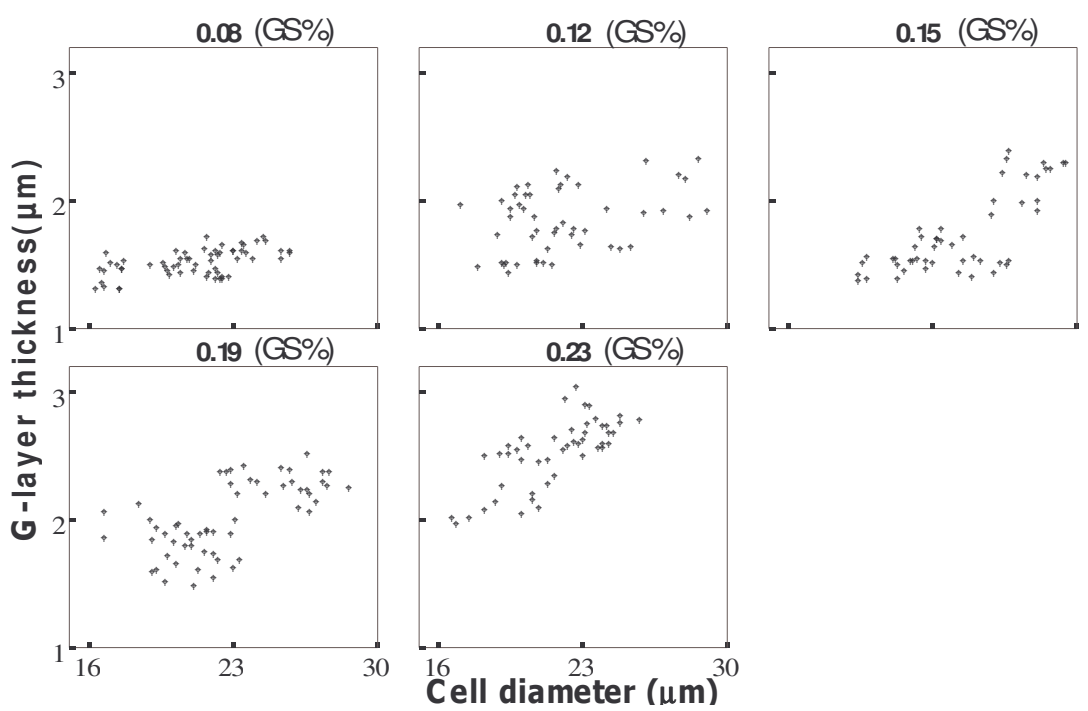

350 Fig. 5. Relation between G-layer thickness $(G L T, \mu \mathrm{m})$ and cell diameter $(F D, \mu \mathrm{m})$ for different GS values (\%).

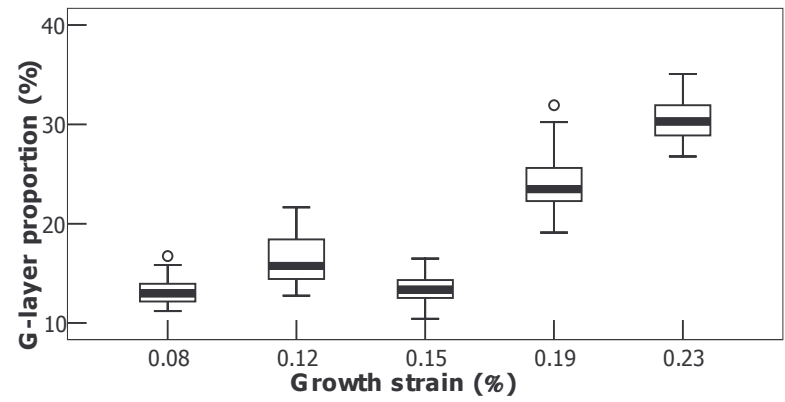

Fig. 6. Relation between G-layer area ratio $\left(G L R_{T}, \%\right)$ and growth strain $(\mathrm{GS}, \%)$. 